\title{
From Business Dining To Public Speaking: Tips For Acquiring Professional Presence And Its Role In The Business Curricula
}

Anna Nicholson Bass, Southeastern Louisiana University, USA

\begin{abstract}
In today's dynamic business environment, organizations are beginning to realize the importance of teaching business etiquette, not only to enhance their corporate culture, but also to increase productivity and profitability. Corporations are providing opportunities for executives of today and business leaders of tomorrow to acquire these vital skills. It is just as important that colleges of business recognize the importance of this "hidden curriculum" and teach it as a vital component of their curricula. Practical advice is proffered to assist in developing a positive, professional demeanor in students.
\end{abstract}

Keywords: Business etiquette, professional presence, business curricula, leadership, communication

\section{INTRODUCTION TO PROFESSIONAL PRESENCE AND ETIQUETTE}

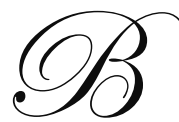

usiness etiquette is a component of an intangible quality called "professional presence," which sets an individual apart and instills a sustainable, competitive advantage. "Manners are a sensitive awareness of the feelings of others. If you have that awareness, you have good manners, no matter what fork you use." (Post, n.d.). These words, written by Emily Post more than 80 years ago, may be surprising, considering that they were penned by a leading authority on the "do's" and "don'ts" of good manners and the author of EtiquetteThe Blue Book of Social Usage. Yet when one considers rules of etiquette, one realizes what Emily Post knew: the foundation of etiquette should be a desire to be considerate of others - to put them at ease and to make everyone around us comfortable in social and in business situations.

In today's competitive global environment, business etiquette plays an increasingly significant role in achieving connectivity among businesspersons in diverse cultures. Executives who want to establish a sustainable competitive advantage are wise to devote attention to business etiquette. Because of its value, corporations are beginning to recognize the teaching of business etiquette as an important part of the education of present and future executives. Armson (2009) proffers that the ability of organizations to thrive, not merely survive, lies in their ability to "create a culture of engaging people at work, engaging the whole person, not just the work-side of the person." And while Armson was not addressing etiquette, he cites Phegan's identification of productive corporate cultures as those possessing respect, genuine communications, personal relationships, and understanding. These qualities are imbedded in the concept of etiquette.

Business etiquette ranks as one of the top three skills lacking among college graduates, according to the National Association of Colleges and Employers' Job Outlook for the Class of 2005 (Jackson, 2005). Cynthia Lett, former chief of protocol and manager of corporate events and meetings for MCI Communications, founded the International Society of Protocol and Etiquette Professionals in 2002. Lett explains that her company, The Lett Group, received more than 140 calls each month from people who needed to hire a corporate etiquette consultant. She says, "Proper business etiquette is nothing more than enjoying doing business with people by treating them with respect." (Blair, 2005). 
Although professional presence is difficult to define, it is easily recognized in the people who possess it. Etiquette is only one vital component of professional presence. What other characteristics and skills form the puzzle pieces that fit together to produce this valuable, intangible quality possessed by successful individuals? The puzzle pieces include self-confidence, an awareness of one's surroundings and the needs of others, integrity, knowledge of "people skills," empathy, and respect for others and oneself - all qualities of a servant leader. In a related vein, Moyes and Redd (2008) while studying job satisfaction among accountants found that job satisfaction had much to do with perceptions of employees as to how employers treated them. Thus, the ability to serve and relate to others is important in the workplace. Think of a leader (for example, a supervisor, director, or colleague) whom you know and admire. Does this individual have professional presence? People who possess this quality radiate the characteristics mentioned above and inspire others to acquire them as well.

How do individuals acquire professional presence and can it be taught? The good news is that it can be mastered by those who have a positive attitude toward themselves and others and who are willing to learn and practice behaviors that will enhance their ability to lead for constructive purposes. In short, it can be taught and should be. People who desire professional presence can benefit from ten practical tips and a number of ways to practice them. Notice the word practice. These tips may sound simple, but they must be consciously and consistently practiced over a period of time. With patience, they should become second nature and provide a competitive advantage that sets an individual apart for success in the business world and in everyday life.

\section{A POSITIVE FIRST IMPRESSION}

Everyone has heard the saying, "You never get a second chance to make a first impression." Never underestimate the power of a first impression. Research indicates that the first information a person sees or learns about another individual is weighted more heavily than information received later (Polak, 2005). The first impression a person makes in a business environment involves the individual's total demeanor. Two important considerations in making a positive impression in business are (1) the manner in which one enters a room and (2) the nonverbal messages one sends within the first few minutes of meeting another individual.

\section{Tip \#1: Make an Effective Entrance}

Although many people give little thought to how they enter a room, their entrance is an important factor in fostering a positive impression. Since an impression begins to develop in the first few moments an individual sees another person, successful leaders give thought to the manner in which they walk into a room. Entering a room in a business setting can be intimidating. Consider entering a large business reception where one knows very few people, or walking into an office where an executive is waiting to interview candidates for the job they have always wanted. The entrance is important and cannot be overstated.

These guidelines are suggested for making an effective entrance:

- When one is nervous about entering a business setting, one should think before entering the room, "What is the impression I want to convey in this situation?" Then visualize a clear, detailed picture of an effective entrance into the room in order to achieve the desired effect. Imagine in detail entering the room. What type of clothing will one wear? How will one stand and move around the room? Imagine confidently making eye contact while greeting others with a smile. Rehearse this mental image vividly and repeatedly.

- Use positive self-talk for reassurance that the entrance will be effective and that any situation that arises can be handled with confidence. Whenever negative thoughts occur, stop immediately and make a conscious effort to replace negative thoughts with constructive self-talk. Many individuals are surprised when they realize how often they mentally "talk" to themselves in a negative manner that they would never use in speaking to another person.

- Be natural; be yourself. This advice is well known, and it works. Think of times in the past when you have experienced success in interacting with others; most likely, you were at ease and were speaking from the heart of the unique person you are. Remember, you are at your best when you value your uniqueness and take the risk of allowing others to know the real "you." 


\section{Tip \#2: Express Confidence through Nonverbal Communication}

Studies show that people place more importance on an individual's nonverbal communication than on the actual words spoken. UCLA psychology professor Albert Mehrabian, a nonverbal communication expert, found that visual components and the way a speaker's voice sounds account for 93 percent of the person's believability, while the words used account for only 7 percent (Clarke, 2005).

Posture is an integral part of nonverbal communication, so if parents or teachers ever told you to watch your posture, they were giving you good advice. The next time you walk down a hallway or a city street, observe people who are walking towards you. Notice your first impression of each individual. Consider the impact each person's posture had on your first impression of that individual. Was it positive or negative? More than likely, the person's posture impacted their presence and your perceptions.

These tips have been recommended for practicing good posture:

- While alone in a room, stand and hold your head level while trying to reach the ceiling with the top of your head. As you use this mental image, you will feel your body straightening so that your entire posture immediately improves. This image is easy to remember and helps you to correct your posture without thinking of multiple instructions, such as "hold your stomach in," and "hold your shoulders back."

- Make a positive impact on others by the way that you move. Walking in a purposeful, yet calm and natural manner, silently communicates self-assurance and trustworthiness.

- Include regular exercise, plenty of water, proper nutrition, and adequate rest in your daily routine. Their benefits will energize you and give a greater feeling of self-confidence, as well as a healthier body.

- $\quad$ Embrace the fact that you will need to devote time and effort to maintain wellness throughout your busy life. The positive impact of caring for yourself will make your dedication to maintaining wellness worthwhile.

\section{PROPER INTRODUCTIONS}

The number of rules that have been written for making introductions can leave us puzzled and ill at ease when we suddenly find ourselves introducing two individuals in a business environment. Who should be introduced to whom? What factors should be considered - age, gender, position in the organization? These considerations can be confusing to someone who must unexpectedly introduce two businesspersons.

\section{Tip \#3: Introduce Individuals Correctly in Business Situations}

- $\quad$ Remember this simple hint to make your introductions smooth and correct: Think of the person you want to honor most, and mention that person's name first (Bixler, 1997). For instance, if you are introducing Ms. Alice Sawyer, vice president of your company, to Mr. Frank Taylor, a coworker and sales representative in your division, you might say, "Ms. Sawyer, I would like to introduce Mr. Fred Taylor. Fred, Ms. Alice Sawyer."

- $\quad$ Follow your introductory statement with a few appropriate comments about the individuals, such as their length of service in the company or a common interest, to enable them to begin talking with one another.

\section{Tip \#4: Shake Hands Effectively with Business Associates}

How many times have you received a handshake that immediately conveyed a poor impression? Successful businesspersons know how to give a positive handshake. Follow these suggestions and practice them with a friend until they become natural for you:

- $\quad$ Maintain eye contact throughout the handshake.

- $\quad$ Talk to the individual while shaking hands.

- $\quad$ Shake hands palm-to-palm rather than palm-to-finger.

- Use a firm, but comfortable grip (Benton, 1992). 


\section{COMMUNICATION SKILLS}

Strong communication skills are highly valued in today's business world. While perusing the employment section of the Sunday edition of a newspaper, circle the advertisements that mention good communication skills as a job requirement. Note the variety of positions requiring strong communication skills in the advertisements you have circled.

Indeed, communication is the cornerstone of effective customer relationship programs. As Chen (2008) points out, customer relationship management is more than salespeople building relationships. Its benefits include using customer feedback to develop new products and developing cost savings measures.

Follow these tips as part of a program to improve your communication skills:

\section{Tip \#5: Develop Listening Skills}

- Become a good listener. Listening is a neglected art; when you learn and practice active listening skills, you will set yourself apart and will likely be regarded as a fascinating conversationalist.

- While most people speak at the rate of 175 to 200 words per minute, research suggests that listeners can process words at a rate of 600 to 1,000 words per minute. To compensate for this time gap, an individual's mind may begin to formulate a reply before the speaker completes the message. Become an active listener, concentrating on what the speaker is saying in order to promote effective communication (Lewis \& Graham, 2003).

- $\quad$ Similarly, realize that feedback that you are receiving allows you to assess whether or not your message was understood. Feedback is a key component of the learning process (Bush et al., 2008).

- Do not interrupt or prevent the speaker from completing the message. When the speaker pauses, wait. Let the speaker resume the conversation (McKenna, 1998).

\section{Tip \#6: Become a Good Conversationalist}

In addition to developing effective listening skills, experts recommend following these suggestions for becoming a good conversationalist:

- $\quad$ Read, read, read. Read a wide variety of publications. On a business trip, buy and read a copy of the local newspaper upon arriving at your destination. You will find information of interest to help you converse with businesspersons at upcoming meetings in that city.

- $\quad$ Keep a story card file. Reflect on your experiences, and use them as a basis for stories you develop. Record these stories in an organized manner on index cards. You can use your anecdotes as effective illustrations of your points during conversation and in your business presentations (Benton, 1996).

- Whenever you have an opportunity to listen to effective speakers, carefully observe and learn from them. Incorporate their strengths into your conversation style.

\section{DINING ETIQUETTE}

Among the hundreds of meetings you may attend throughout your business career, some of the most challenging are luncheon and dinner meetings. Your manners at business meals can affect your success in being hired and promoted and in conducting business with clients. Consider the following tips:

\section{Tip \#7: Order Appropriate Food at a Business Meal}

- $\quad$ Order food that you like and can eat easily and neatly. Avoid messy soups and spaghetti dishes, for example.

- $\quad$ Select a food item in the middle price range. You may want to ask the host for a suggestion by asking, "What do you recommend?" (Joyce, 2005). 


\section{Tip \#8: Dine Correctly at Business Meals}

Brooke Hodges, training manager for the Bank of America, deliberately takes job candidates to lunch and observes their etiquette, courtesy, and respect for others during the meal. She gives the following etiquette tips for a business meal:

- $\quad$ Pace yourself throughout the meal so that you will be neither the first nor the last person to finish eating.

- $\quad$ Cut and eat one piece of food at a time.

- $\quad$ After using a utensil, do not let it touch the table again.

- $\quad$ Blot, rather than wipe, your mouth with a napkin.

- When in doubt, follow the host of the table (Torres, 2005).

Begin practicing correct dining etiquette today, whether you are eating alone, with your family, or with friends. In a business situation, concentrating on the business at hand demands attention. In these situations, people revert to dining manners they use on a daily basis - the ones that have become second nature.

\section{PUBLIC SPEAKING}

\section{Tip \#9: Plan Your Presentation}

Fear of public speaking is the most common social phobia and is experienced by approximately 75 percent of the population (Brewer, 2005). With dedicated practice of the following tips, you can alleviate fears that may arise when you are asked to speak publicly:

- $\quad$ First, consider your audience. Learn everything possible about the composition of your audience-their ages, backgrounds, purposes for attending your presentation. Tailor your presentation to meet their needs.

- $\quad$ Experts recommend organizing your talk into three parts: (1) Tell your audience what you are going to tell them (a brief overview of your presentation); (2) Tell them (the body of your talk); and (3) Tell them what you told them (a brief summary). Arranging your presentation in this way provides structure and gives you a framework to use in developing your message.

- When you have carefully planned your presentation, practice a number of times before the event. Do not memorize your talk, but present it using an outline so that you can speak more naturally. Practice before friends and by yourself in front of a full-length mirror. Be certain that the length of your speech will allow you to finish speaking within the time allotted for your presentation.

- Use appropriate gestures to enhance your delivery. Practice these gestures as you rehearse your talk before the mirror. A videotape of one of your practice sessions can help you identify areas for improvement.

- Wear the clothing you plan to wear for the presentation several times before the actual event. You may want to make an unanticipated adjustment in the clothing before the date of your talk, or you may decide to wear another article of clothing instead. Wearing clothes you have previously worn will help you feel more at ease and less self-conscious.

\section{Tip \#10: Present for Business Success}

Realize that your audience forms a first impression of your reliability and expertise based on your nonverbal messages long before you begin to speak. Consider these suggestions in delivering your next business presentation:

- $\quad$ Be aware of your posture and demeanor while entering the room and sitting in view of the audience before your speech.

- Walk confidently and purposefully to the podium. Experts suggest pausing as soon as you reach the podium to look calmly, pleasantly, and directly at your audience before beginning to speak. This pause conveys confidence and captures their attention before you begin.

- $\quad$ Speak clearly and naturally; do not hurry. 
- $\quad$ Be conscious of what you are doing while speaking; avoid distracting mannerisms.

- To alleviate nervousness while practicing or delivering your speech, remember to concentrate on the message you want to convey to your listeners. Each time you begin to feel nervous, recall your desire to communicate an important message to them. Thinking about your message rather than your nervousness will calm you and dramatically increase your effectiveness as a speaker (Timm, 1997).

\section{CONCLUSION: THE KEY TO PROFESSIONAL PRESENCE}

Learning and practicing suggestions for establishing professional demeanor are vital steps along the path to a successful career. Tips for acquiring professional presence are valuable tools, but they must be built upon a solid foundation of consideration for the feelings and well-being of other people. In today's dynamic business environment, we must attempt to examine situations from a variety of viewpoints. In essence, we must be kind to each other. Successful businesspersons are leaders who have learned - and continue to develop - traits and skills that contribute to their ability to bring out the best in the people they lead.

Business etiquette and developing a professional presence can be easily incorporated in business curricula. For instance, many business schools require students to take a course in business communication/presentations. Surely, inserting a unit on business etiquette and professional presence into such a course would require minimal effort. In total though, the importance of etiquette and professional presence is such that a course devoted entirely to the subject is recommended for all.

\section{AUTHOR INFORMATION}

Anna Nicholson Bass teaches management courses in the classroom and on the Internet at Southeastern Louisiana University. She serves as an executive etiquette consultant to business and civic organizations and has been a guest speaker in the graduate program at Loyola University, the 2009 Women Empowered Conference, the United States Army Reserve Command, the Louisiana Institute for Administrative Assistants, and the Baton Rouge chapter of the National Association of Purchasing Managers.

Ms. Bass, who holds an MBA degree, is a member of Beta Gamma Sigma and has been honored by the National Parent Teacher Association with a Lifetime Membership Award.

\section{REFERENCES}

1. Armson, G. (2009, January/February). Exploring a 'space' for emergent learning to occur: Encouraging creativity and innovation in the workplace. American Journal of Business Education, Vol. 2, No. 1, 1-16.

2. Benton, D.A. (1996). How to think like a CEO. New York: Warner Books, Inc.

3. Benton, D.A. (1992). Lions don't need to roar. New York: Warner Books, Inc.

4. Bixler, S. (1997). The new professional image. Holbrook, MA: Adams Media Corporation.

5. Blair, B. (2005, May 1). Q\&A with the queen of international protocol. Corporate Meetings and Incentives. Retrieved July 1, 2005, from http://web.lexisnexis.com/universe/document? $\mathrm{m}=37 \mathrm{~b} 76 \mathrm{~d} 64 \mathrm{a} 0 \mathrm{dd} 28700 \mathrm{e} 511 \mathrm{ac} 4 \mathrm{~d} 8 \mathrm{bb} 822 \mathrm{~d} \&$ docnum $=2 \& \mathrm{wchp}=\mathrm{dGLbVtz}$ -zSkVA\& md5=4a0fa3c8f4a0c876c0853ee8cb9437a5

6. Brewer, S. (2005). The fear and anxiety of speaking in public. Fort McMurray Today [Alberta]. Retrieved June 27, 2005, from http://web.lexisnexis.com/universe/document? $\mathrm{m}=05 \mathrm{~b} 0 \mathrm{~d} 6 \mathrm{ca} 2967802 \mathrm{c} 9 \mathrm{db} 2482 \mathrm{ba} 555 \mathrm{a} 501 \&$ docnum $=2 \& w \mathrm{w} h \mathrm{p}=\mathrm{dGLbVtb}$ -ZSkVA\& md5=c271407330986dca5c5120e18236f8e1

7. Bush, H. F., Squire, J., Sullivan, G., Walsh, V., English, A. and Bolen, R. (2008, $4^{\text {th }}$ Quarter). An investigation of the effect of network latency on pedagogic efficacy: A comparison of Disciplines. Contemporary Issues in Education Research, Vol. 1, No. 4, pp. 11-25.

8. Chen, K. C. (2008, June). The dynamic structure of customer relationship management with implications for business implementation. Journal of Business and Economics Research, Vol. 6, No. 6, pp. 128-139. 
9. Clarke, R. (2005). Walk your talk. Black Enterprise. Retrieved July 1, 2005, from http://web.lexisnexis.com/universe/document? $\mathrm{m}=3 \mathrm{ab} 534 \mathrm{~b} 6 \mathrm{f} 4 \mathrm{eb} 32 \mathrm{~d} 9 \mathrm{c} 874 \mathrm{f} 97033 \mathrm{fcb} 79 \mathrm{f} \&$ docnum=9\&wchp=dGLbVtbzSkVA\&_md5=e43f0336b5036e99282b76f6c8609602

10. Jackson, K. (2005). Just graduated? Know the rules of business etiquette. The Boston Globe. Retrieved July 1, 2005, from http://web.lexisnexis.com/universe/document?_m=58d8ee2f4f17496ad5bd98f93435a565\&_docnum=6\&wchp=dGLbVtzzSkVA\&_md5=d19e70c615312c72cfc245a0ec96a293

11. Joyce, E. (2005). The business meal is never about the food. Copley News Service. Retrieved July 1, 2005 , from http://web.lexisnexis.com/universe/document? $\mathrm{m}=7497111645 \mathrm{c} 04 \mathrm{eaca} 152 \mathrm{ff} 2 \mathrm{a} 25 \mathrm{~b} 1 \mathrm{ffe} 9 \&$ docnum $=1 \& \mathrm{wchp}=\mathrm{dGLbVtb}-$ zSkVA\&_md5=fadcde4e03eb09610cdc0107354f2b20

12. Lewis, T. and Graham, G. (2003, August). 7 tips for effective listening: Productive listening does not occur naturally. Internal Auditor. Retrieved August 11, 2009, from http://findarticles.com/p/articles/mi_m4153/is_4_60/ai_106863366/?tag=content;col1

13. McKenna, C. (1998). Powerful communication skills. Franklin Lakes, NJ: Career Press.

14. Moyes, G. D. and Redd, T. C. (2008, October). Empirical analysis of factors influencing the level of job satisfaction of Caucasian and Hispanic accounting professionals. International Business and Economics Research Journal, Vol. 7, No. 10, pp. 21-42.

15. Polak, M. (2005). A first impression can stick. The Gazette [Montreal]. Retrieved June 28, 2005, from http://web.lexis-

nexis.com/universe/document? m=b181e6d84ff4a264b53cbfe3e2cb6997\& docnum=1\&wchp=dGLbVtbzSkVA\&_md5=ebba9b67bb9f42996b0ab2aa2c12d399

16. Post, Emily. (n.d.) Bartleby.com. Retrieved June 22, 2005, from http://www.bartleby.com/sv/postquotes.html

17. Timm, P. (1997). How to make winning presentations; 30 action tips for getting your ideas across with clarity and impact. Franklin Lakes, NJ: Career Press.

18. Torres, B. (2005). Mind your manners; job candidates having lunch with an interviewer score more points when they know their etiquette. The Baltimore Sun. Retrieved June 28, 2005, from http://web.lexisnexis.com/universe/document? $\mathrm{m}=0 \mathrm{e} 7 \mathrm{e} 1 \mathrm{bfa} 89985137943934 \mathrm{~b} 9 \mathrm{~d} 062 \mathrm{~d} 45 \mathrm{c} \&$ docnum $=10 \& \mathrm{wchp}=\mathrm{dGLbVt}$ b-zSkVA\&_md5=f6ea9dd76f88de577bbc1b1ccb57a9e9 


\section{NOTES}

